\title{
Identification and functional analysis of the genes for naphthalenesulfonate catabolism by Sphingomonas xenophaga BN6
}

\author{
Andreas Keck, ${ }^{1} \dagger$ Doris Conradt, ${ }^{1}$ Anette Mahler, ${ }^{1}$ Andreas Stolz, ${ }^{2}$ \\ Ralf Mattes ${ }^{1}$ and Joachim Klein ${ }^{1} \ddagger$
}

Correspondence

Joachim Klein

joachim.klein@lonza.com

Received 19 December 2005

Revised 13 March 2006

Accepted 14 March 2006
Institut für Industrielle Genetik ${ }^{1}$ and Institut für Mikrobiologie ${ }^{2}$, Universität Stuttgart, Allmandring 31, D-70569 Stuttgart, Germany

Sphingomonas xenophaga BN6 degrades various (substituted) naphthalenesulfonates to the corresponding (substituted) salicylates. A gene cluster was identified on the plasmid pBN6 which coded for several enzymes participating in the degradative pathway for naphthalenesulfonates. A DNA fragment of 16915 bp was sequenced which contained 17 ORFs. The genes encoding the 1,2-dihydroxynaphthalene dioxygenase, 2-hydroxychromene-2-carboxylate isomerase, and 2 '-hydroxybenzalpyruvate aldolase of the naphthalenesulfonate pathway were identified on the DNA fragment and the encoded proteins heterologously expressed in Escherichia coli. Also, the genes encoding the ferredoxin and ferredoxin reductase of a multi-component, ring-hydroxylating naphthalenesulfonate dioxygenase were identified by insertional inactivation. The identified genes generally demonstrated the highest degree of homology to enzymes encoded by the phenanthrene-degrading organism Sphingomonas sp. P2, or the megaplasmid pNL1 of the naphthalene- and biphenyl-degrading strain Sphingomonas aromaticivorans F199. The genes of S. xenophaga BN6 participating in the degradation of naphthalenesulfonates also shared the same organization in three different transcriptional units as the genes involved in the degradation of naphthalene, biphenyl, and phenanthrene previously found in Sphingomonas sp. P2 and S. aromaticivorans F199. The genes were flanked in S. xenophaga BN6 by ORFs which specify proteins that show the highest homologies to proteins of mobile genetic elements.

\section{INTRODUCTION}

Substituted naphthalenesulfonic acids (NSAs) are commonly used as detergents, dispersants and building blocks for the synthesis of azo dyes and various other products of the chemical industry (Tully, 1997). Since arylsulfonates are very rarely found in nature, NSAs are referred to as xenobiotics. Naphthalenesulfonates are only slowly degraded in the environment and have been repeatedly isolated from contaminated environments (Wellens, 1990; Alonso et al., 1999; Riediker et al., 2000; Ruckstuhl et al., 2002).

†Present address: Deutsches Ressourcenzentrum für Genomforschung, Heubnerweg 6, 14059 Berlin, Germany.

$\ddagger$ Present address: Lonza AG, Biotechnology Research and Development, $\mathrm{CH}-3930$ Visp, Switzerland.

The GenBank/EMBL/DDBJ accession number for the sequence determined in this work is U65001.

Abbreviations: DHNDO, 1,2-dihydroxynaphthalene dioxygenase; 2NSA, naphthalene-2-sulfonic acid; NSA, naphthalenesulfonic acid; NsaA, naphthalenesulfonate dioxygenase; NsaC, 1,2-dihydroxynaphthalene dioxygenase; NsaD, 2-hydroxychromene-2-carboxylate isomerase; NsaE, 2'-hydroxybenzalpyruvate aldolase; NsaF, salicylaldehyde dehydrogenase.
Nevertheless, several bacterial strains have been isolated which convert different naphthalenesulfonates (Brilon et al., 1981a, b; Ohe \& Watanabe, 1986, 1988; Wittich et al., 1988; Zürrer et al., 1987). The most intensively studied bacterial strain with the ability to degrade naphthalenesulfonates is Sphingomonas xenophaga BN6, which degrades various amino- and hydroxynaphthalenesulfonates to the corresponding amino- or hydroxysalicylic acids (Nörtemann et al., 1986, 1994; Stolz et al., 2000). The catabolism of the naphthalenesulfonates by $S$. xenophaga BN6 is initiated by an oxygenolytic desulfonation of the substrates in connection with a spontaneous rearomatization to the corresponding (substituted) 1,2-dihydroxynaphthalenes (Fig. 1). The following enzymic steps are identical in the degradative pathways of naphthalene and naphthalenesulfonates. The (substituted) 1,2-dihydroxynaphthalenes are cleaved by a 1,2-dihydroxynaphthalene dioxygenase (NsaC) to 2-hydroxychromene-2-carboxylates, which are converted by a 2-hydroxychromene-2-carboxylate isomerase (NsaD) to trans-2'-hydroxybenzalpyruvates, which are finally converted by $2^{\prime}$-hydroxybenzalpyruvate aldolase/hydratases (NsaEs) to pyruvate and (substituted) salicylaldehydes. Several of these key enzymes of the naphthalenesulfonate 


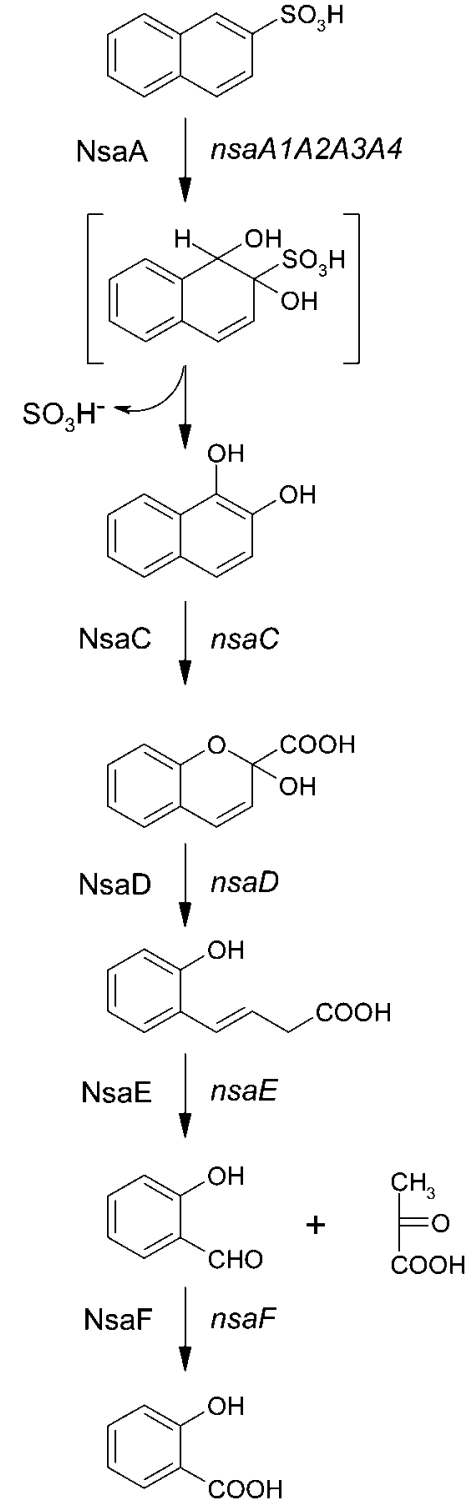

Fig. 1. Pathway for naphthalenesulfonate degradation by $S$. xenophaga BN6.

degradative pathway have been studied in S. xenophaga (Kuhm et al., 1991a; Stolz, 1999). Three of the relevant enzymes, NsaC, $\mathrm{NsaD}$ and $\mathrm{NsaE}$, have been purified and biochemically characterized. Furthermore, the N-terminal amino acid sequences of $\mathrm{NsaC}$ and $\mathrm{NsaE}$ have been determined (Kuhm et al., 1991a, 1992, 1993).

The genes for two extradiol dioxygenases ( $\mathrm{BphC1}$ and BphC2) have been cloned from S. xenophaga BN6 by screening of a gene bank for 2,3-dihydroxybiphenyl dioxygenase activity (Heiss et al., 1995, 1997), but sequence and biochemical data show that the two extradiol dioxygenases are not involved in the degradation of NSAs. Recently, the genes for the degradation of NSAs have been localized on a $180 \mathrm{~kb}$ megaplasmid in S. xenophaga BN6 (Basta et al.,
2004). Therefore, in the present study, the relevant gene cluster was analysed in detail.

\section{METHODS}

Bacterial strains, plasmids, media and growth conditions. The bacterial strains and plasmids used and their relevant characteristics are listed in Table 1. The isolation and characterization of S. xenophaga BN6 has been described previously (Nörtemann et al., 1986; Stolz et al., 2000). The strain has been deposited at the Deutsche Sammlung von Mikroorganismen und Zellkulturen, Braunschweig, Germany, as DSM 6383. Strain BN6 was either grown in nutrient broth or a mineral medium (Dorn et al., 1974) supplemented with glucose (MMG, $25 \mathrm{mM}$ ), naphthalene-2-sulfonic acid (2NSA, $5 \mathrm{mM})$, glucose $(25 \mathrm{mM})$ and 2NSA $(1 \mathrm{mM})$, or 6-aminonaphthalene-2-sulfonic acid (5 mM).

All cloning experiments and plasmid preparations were carried out in Escherichia coli JM109 (Viera \& Messing, 1982). E. coli strains carrying different plasmids were grown at $37^{\circ} \mathrm{C}$ in $2 \times$ yeast tryptone (YT) liquid medium or on $2 \times$ YT agar plates (Sambrook et al., 1989). The antibiotics ampicillin, kanamycin and tetracycline were used at final concentrations of 100,50 and $20 \mu \mathrm{g} \mathrm{ml}^{-1}$, respectively.

DNA manipulation and preparation, cell transformation, and conjugation. Small-scale plasmids were prepared by the method of Kieser (1984). Genomic DNA was isolated and all manipulations were carried out as described by Sambrook et al. (1989). All enzymes were purchased from Roche Diagnostics and used according to the manufacturer's suggestions. E. coli was transformed with plasmid DNA by the method of Chung et al. (1989). The conjugation experiments were performed as described by Keck et al. (1997).

PCR amplification of the 1,2-dihydroxynaphthalene dioxygenase (DHNDO) gene fragment. The PCR reaction mixtures contained, in a volume of $40 \mu \mathrm{l}, 10-100 \mathrm{ng}$ genomic DNA, $0.5 \mu \mathrm{M}$ of each forward and reverse primer (MWG-Biotech), $10 \mathrm{mM}$ Tris/ $\mathrm{HCl}(\mathrm{pH} 9 \cdot 0), 50 \mathrm{mM} \mathrm{KCl}, \quad 1.5 \mathrm{mM} \mathrm{MgCl}_{2}, 0.2 \mathrm{mM}$ dNTPs (Pharmacia Biotech) and $2.5 \mathrm{U}$ Taq DNA polymerase (Pharmacia Biotech). The amino acid sequences GYLGM and WRAYAA found at the $\mathrm{N}$ terminus of DHNDO (Kuhm et al., 1991a) were used to design the primers $5^{\prime}$-GGY-TAY-CTS-GGY-ATG-3' (DHNDO1, coding strand) and 5'-GC-SGC-RTA-SGC-SCG-CCA-3' (DHNDO2, non-coding strand). The Pseudomonas codon usage was used (Wada et al., 1992). The mixtures were placed in a thermal cycler (PTC200; MJ Research). The first step consisted of denaturation for $1 \mathrm{~min}$ at $94^{\circ} \mathrm{C}$, followed by 30 cycles of denaturation for $1 \mathrm{~min}$ at $92^{\circ} \mathrm{C}$, annealing of primers for $1 \mathrm{~min}$ at $35^{\circ} \mathrm{C}$ and extension for $2 \mathrm{~min}$ at $72^{\circ} \mathrm{C}$, with extension for $5 \mathrm{~min}$ during the last cycle. The PCR fragments were separated by electrophoresis through $1 \%$ agarose gels at $10 \mathrm{~V} \mathrm{~cm}^{-1}$ and stained by ethidium bromide.

Nucleotide sequence analysis. The DNA sequence was determined by the dideoxy chain-termination method in an automated DNA sequencer (ALF-Sequencer; Pharmacia Biotech) by use of reverse primers, sequencing primers or primers which were derived from known sequences. Database searches were done online with the programs BLASTX, BLASTP and BLASTN provided by the BLAST E-mail server (Altschul et al., 1990; Gish \& States, 1993). CLUSTALW (Thomson et al., 1994) was used to align the amino acid sequences. All parameters were set at their default values. The sequence alignments were edited and analysed by using the multiple sequence alignment editor and shading utility GeneDoc (version 1.1.004) (Nicholas \& Nicholas, 1996).

Isolation of the genomic DNA region. The $1.3 \mathrm{~kb}$ PCR fragment was treated with the Klenow fragment of DNA polymerase I 
Table 1. Bacterial strains and plasmids

SOE, splicing by overlap extension.

\begin{tabular}{|c|c|c|}
\hline Strain or plasmid & Relevant characteristics ${ }^{\star}$ & Source or reference \\
\hline \multicolumn{3}{|l|}{ Strains } \\
\hline S. xenophaga BN6 & & Stolz et al. (2000) \\
\hline Wild-type (DSM 6383) & $\mathrm{NSA}^{+}$ & Nörtemann et al. (1986) \\
\hline AKE2 & $\Delta$ ORF6:: nptII $(\Delta n s a A 1), \mathrm{Km}^{\mathrm{r}}$ & This study \\
\hline AKE3 & $\Delta$ ORF9:: nptII ( $\Delta n s a A 2), \mathrm{Km}^{\mathrm{r}}$ & This study \\
\hline AKE4 & $\Delta$ ORF8 : : nptII ( $\Delta n s a A 3), \mathrm{Km}^{\mathrm{r}}, \mathrm{NSA}^{-}$ & This study \\
\hline AKE5 & $\Delta$ ORF16:: nptII $(\Delta n s a A 4), \mathrm{Km}^{\mathrm{r}}, \mathrm{NSA}^{-}$ & This study \\
\hline \multicolumn{3}{|l|}{ E. coli } \\
\hline JM109 & $\begin{array}{l}\text { endA1 recA1 gyrA96 thi hsdR17 relA1 supE44 } \Delta(\text { lac-proAB }) \\
\mathrm{F}^{\prime}\left[\text { traD36 proAB lacl }{ }^{\mathrm{q}} \text { lacZ } \Delta \mathrm{M} 15\right]\end{array}$ & Yanisch-Perron et al. (1985) \\
\hline S17-1 & recA pro $h s d R h s d M^{+} \mathrm{RP} 4\left(\mathrm{Tc}:: \mathrm{Mu}, \mathrm{Km}:: \mathrm{Tn} 7, \mathrm{Tp}^{\mathrm{r}}, \mathrm{Sm}^{\mathrm{r}}\right)$ & Simon et al. (1983) \\
\hline \multicolumn{3}{|l|}{ Plasmids } \\
\hline pAKE16 & ORF5 in pJOE2702; $\mathrm{Amp}^{\mathrm{r}}$ & This study \\
\hline pAKE17 & ORF13 in pJOE2702; $A_{m p}{ }^{r}$ & This study \\
\hline pAKE18 & ORF12 in pJOE2702; $A_{m p}{ }^{r}$ & This study \\
\hline pAKE3-5 & RTS1, $12 \mathrm{~kb}$ genomic insert of strain BN6 & This study \\
\hline pAKE35.1 & $s a c B$ in pMHS298 & This study \\
\hline pAKE36 & SOE fragment of ORF6 in pAKE35.1; $\mathrm{Tc}^{\mathrm{r}} \mathrm{Km}^{\mathrm{r}}$ & This study \\
\hline pAKE37 & SOE fragment of ORF8 in pAKE35.1; $\mathrm{Tc}^{\mathrm{r}} \mathrm{Km}^{\mathrm{r}}$ & This study \\
\hline pAKE39 & SOE fragment of ORF9 in pAKE35.1; $\mathrm{Tc}^{\mathrm{r}} \mathrm{Km}^{\mathrm{r}}$ & This study \\
\hline pAKE41 & SOE fragment of ORF16 in pAKE35.1; $\mathrm{Tc}^{\mathrm{r}} \mathrm{Km}^{\mathrm{r}}$ & This study \\
\hline pJKS325 & ORF7 in pJOE2702; $\mathrm{Amp}^{\mathrm{r}}$ & This study \\
\hline pJOE2702 & $P_{\text {rha }} A m p^{r}$ & Volff et al. (1996) \\
\hline pJOE890 & Positive selection vector & Altenbuchner et al. (1992) \\
\hline pJKS240 & $1 \cdot 3 \mathrm{~kb}$ fragment in pJOE890 & This study \\
\hline pMHS298 & Mobilizable plasmid; $A m p^{r} \mathrm{Tc}^{\mathrm{r}}$ & Hils (1998) \\
\hline
\end{tabular}

${ }^{\star} \mathrm{NSA}^{+}$, degradation of naphthalenesulfonate; $\mathrm{NSA}^{-}$, mutant of strain BN6 which had lost NSA degradation activity.

(Boehringer Mannheim) and inserted into EcoRV-cut pJOE890 (Altenbuchner et al., 1992) to yield pJKS240. A $\lambda$ RES vector, with a built-in Tn1721-encoded excision system (Altenbuchner, 1993), was used to construct a genomic library of the wild-type $S$. xenophaga BN6. The PCR fragment was DIG-labelled to identify the phage carrying the relevant genomic region. One of the identified phages was converted into the RTS1-derived pAKE3-5 (Altenbuchner, 1993).

Hybridization of DNA. Total genomic DNA was isolated and digested with restriction endonucleases. After electrophoresis, the DNA was transferred onto a positively charged nylon membrane (Roche Diagnostics). Probe DNA was DIG-labelled by use of a DNA labelling and detection kit (Roche Diagnostics). Hybridization was carried out at $68^{\circ} \mathrm{C}$ in hybridization buffer, as described by the manufacturer. The Southern blots were developed using chemiluminescent detection, according to the protocol of the DNA labelling and detection kit.

Inverse PCR. Inverse PCR was performed, as described by Ochman et al. (1988), to isolate the $5^{\prime}$ and $3^{\prime}$ flanking sequences of the genomic sequence fragment of pAKE3-5. To isolate the $5^{\prime}$ flanking sequence, genomic DNA of strain BN6 was cut with HindIII and hybridized against the chromosomal fragment of pAKE3-5. The hybridization signal corresponded to a fragment of $3.5 \mathrm{~kb}$ for the additional $5^{\prime}$ sequence. The DNA of strain BN6 was cut with HindIII, ligated and used for PCR studies (forward primer S1659, 5'-GAC-GAT-GAG-CAG-GTA-GAA-CT-3'; reverse primer S1660,
5'-ACC-TTC-ATC-ATG-TCG-TCT-TC-3'). To isolate the $3^{\prime}$ flanking sequence, genomic DNA of $S$. xenophaga BN6 was cut with PstI and hybridized against the $12 \mathrm{~kb}$ chromosomal insert of pAKE3-5. The hybridization signal corresponded to a fragment of $\sim 1.5 \mathrm{~kb}$ for the additional 3' sequence. Thus, genomic DNA of strain BN6 was cut with PstI and ligated in different concentrations (100 ng, $1 \mu \mathrm{g}$ ). The ligated DNA was used for PCR with the primer pair S2124 (5'-GCA-AAT-CGT-CGT-CAG-GAT-TA-3') and S2125 (5'-GCGCCG-ACT-GTT-ATC-TTC-TT-3'). The $5^{\prime}(3.5 \mathrm{~kb})$ and $3^{\prime}(1.5 \mathrm{~kb})$ flanking fragments of the genomic DNA region were cloned into EcoRV-cut pUC18 and sequenced.

Subcloning of ORF5, ORF7, ORF12 and ORF13 into pJOE2702. The primers which were used for the subcloning experiments are summarized in Table 2. The forward primer S1817 and the reverse primer S1818 were used to amplify a 1519 bp fragment containing the ORF5 gene. The PCR was performed as described for the DHNDO gene fragment. The primer pairs S1252/S1352, S1821/ S1822 and S1823/S1824 were used to generate PCR fragments of ORF7 (916 bp), ORF12 (607 bp) and ORF13 (1006 bp), respectively. To facilitate cloning of the PCR products, NdeI and BamHI restriction sites were added to the primers. The appropriate PCR products were cut with $\mathrm{NdeI}$ and BamHI and inserted into NdeI/ BamHI-cleaved pJOE2702 (Volff et al., 1996) to give pAKE16 (ORF5), pJKS325 (ORF7), pAKE18 (ORF12) and pAKE17 (ORF13). E. coli strains JM109(pAKE16), JM109(pJKS325), JM109(pAKE18) 
Table 2. Oligonucleotides used in this study for the cloning of the gene encoding NsaC, and the construction of expression vectors and hybrid genes by splicing by overlap extension.

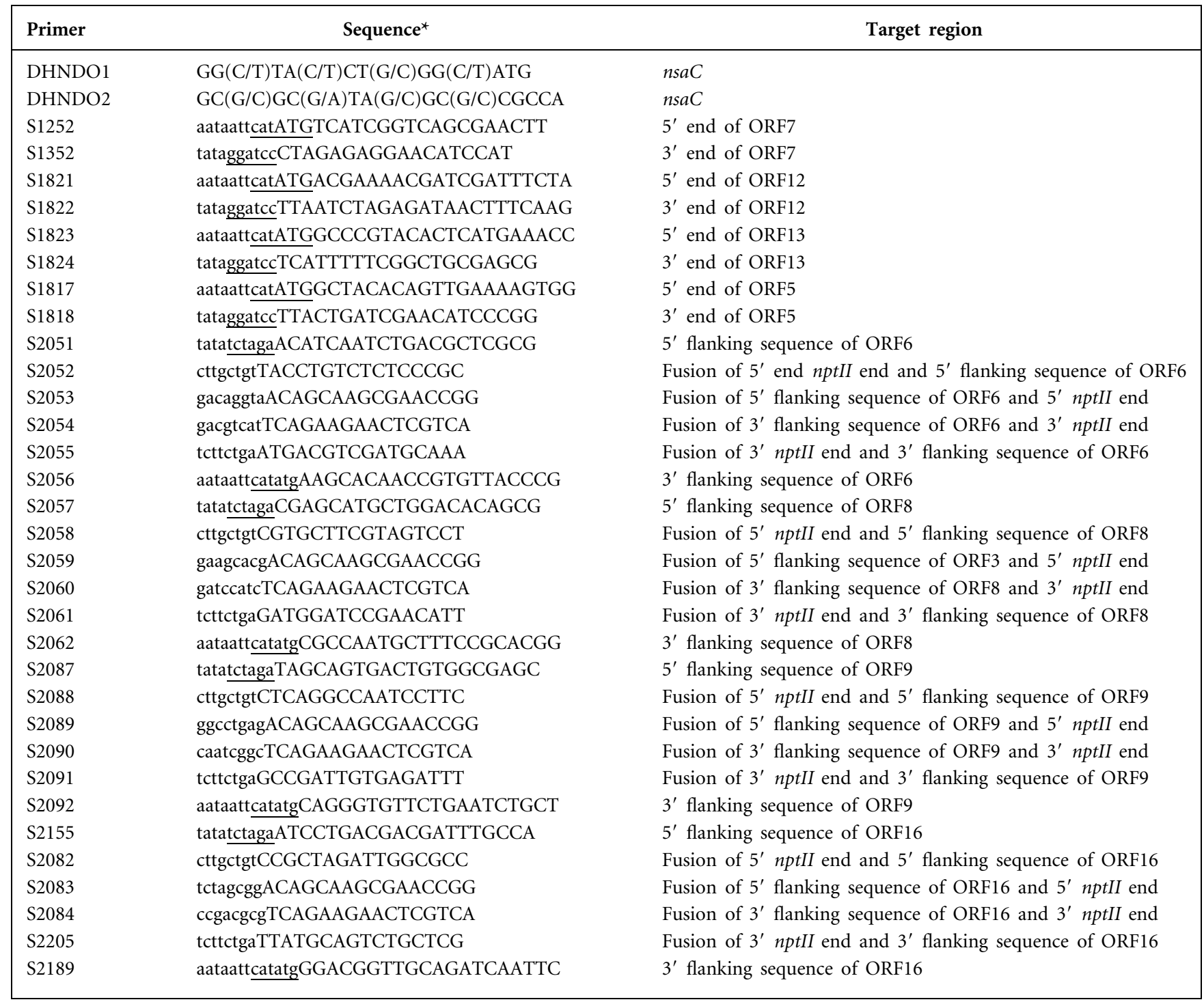

${ }^{\star}$ Relevant recognition sequences for the restriction enzymes NdeI, BamHI and XbaI are underlined. Lower-case type indicates the sequences which are not homologous to the template DNA.

and JM109(pAKE17) were each grown to the early exponential growth phase $\left(\mathrm{OD}_{600} 0 \cdot 3\right)$ and induced for $4 \mathrm{~h}$ with $0 \cdot 2 \%(\mathrm{w} / \mathrm{v})$ rhamnose. The cell extracts were analysed by $12 \%(\mathrm{w} / \mathrm{v})$ SDS-PAGE.

Insertional inactivation of ORF6, ORF8, ORF9 and ORF16 in S. xenophaga BN6. The DNA fragments to be joined were amplified in separate PCRs, cut with $\mathrm{XbaI} / \mathrm{NdeI}$ and inserted into the $\mathrm{XbaI} /$ NdeI-cut mobilizable pAKE35.1 (Table 1). The ORFs were deleted and replaced by the kanamycin-resistance gene (nptII) of Tn5. The chromosomal regions for homologous recombination of the $5^{\prime}$ and $3^{\prime}$ flanking regions of the inactivated gene, which were ligated to the $n p t I I$ gene, were set to $\sim 1 \mathrm{~kb}$. This resulted in pAKE36 (for ORF6), pAKE37 (for ORF8), pAKE39 (for ORF9) and pAKE41 (for ORF16). The plasmids were transferred separately from E. coli S17-1 (Simon et al., 1983) to S. xenophaga BN6 by conjugation. Since pAKE35.1 $\left(\mathrm{Tc}^{\mathrm{r}}\right)$ does not replicate in strain BN6, integration mutants were selected on MMG agar plates supplemented with tetracycline. To isolate integration mutants which had lost the vector fragment by homologous recombination, the strains were selected on MMG supplemented with sucrose (4\%) and kanamycin. Genomic DNA was isolated, digested with different restriction enzymes and hybridized against the deleted gene, the nptII gene and the $5^{\prime}$ and $3^{\prime}$ flanking fragments of the deleted gene, to verify the integration of the nptII gene into the corresponding gene. The primers used are listed in Table 2, and the procedure was performed as described previously (Keck et al., 2002).

Preparation of cell extracts. Cells were harvested by centrifugation at $6000 \mathrm{~g}$, washed with $5 \mathrm{ml}$ and resuspended in $1 \mathrm{ml} 50 \mathrm{mM}$ sodium/potassium phosphate buffer $(\mathrm{pH} 7 \cdot 3)$. The cells were disrupted by sonication (Ultrasonics Sonicator W-385; Heat SystemsUltrasonics; Microtip, $2 \times 30 \mathrm{~s}$, duty cycle $50 \% \mathrm{~s}^{-1}$ ). Cell debris was 
removed by centrifugation for $30 \mathrm{~min}$ at $100000 \mathrm{~g}$. Protein concentrations were determined according to the method of Bradford (1976), by use of the Bio-Rad protein assay.

Enzyme assays. The naphthalenesulfonate dioxygenase (NsaA) activity was quantified, as described by Nörtemann et al. (1986), using resting cells of strain BN6 incubated with 2NSA (1 mM), and is given as nanomoles of 2NSA transformed per minute per milligram of protein present in the crude extract (Nörtemann et al., 1994). The NSA degradation pathway was induced by the addition of $0.5 \mathrm{mM}$ salicylate to the exponentially growing cells and the culture was further incubated at $30^{\circ} \mathrm{C}$ for $3 \mathrm{~h}$.

NsaC and salicylaldehyde dehydrogenase (NsaF) activity were measured as described by Kuhm et al. (1991a, b). NsaE and NsaD were assayed spectrophotometrically, as described by Kuhm et al. (1992, 1993).

SDS-PAGE. The proteins were separated on a $12 \%(\mathrm{w} / \mathrm{v})$ denaturing polyacrylamide gel by use of the discontinuous buffer system described by Laemmli (1970) and stained with Coomassie blue R250.

HPLC analysis. The degradation of NSA was monitored by HPLC (Lichrograph L-6200 gradient pump equipped with a L-4200 UV-VIS detector; Merck). A reversed-phase column $(250 \times 4 \mathrm{~mm}$ internal diameter; GROM), filled with $5 \mu \mathrm{m}$ diameter particles of Lichrospher RP18 (Merck), was used to identify individual compounds which were detected spectrophotometrically at $210 \mathrm{~nm}$. The mobile phase consisted of $50 \%(\mathrm{v} / \mathrm{v})$ methanol, $49 \cdot 75 \%$ (v/v) $\mathrm{H}_{2} \mathrm{O}$ and $0 \cdot 25 \%(\mathrm{v} / \mathrm{v}) \mathrm{H}_{3} \mathrm{PO}_{4}$, and the flow rate was $1 \mathrm{ml} \mathrm{min}^{-1}$.

Chemicals. NSAs were obtained from Bayer. 2'-Hydroxybenzalpyruvate was kindly provided by A. Kuhm, Institut für Mikrobiologie, Stuttgart. 2-Hydroxychromene-2-carboxylate was prepared enzymically with whole cells of strain BN6, as described by Kuhm et al. (1993). All other chemicals were obtained from Sigma-Aldrich or Merck. Biochemicals were from Boehringer Mannheim.

\section{RESULTS}

\section{Cloning of the gene encoding NsaC}

The NsaC of strain BN6 was previously purified and characterized, and the $\mathrm{N}$-terminal amino acid sequence determined (Kuhm et al., 1991a). The primers DHNDO1 and DHNDO2 (Table 2) were derived from the N-terminal amino acid sequence and used for the attempted amplification of the corresponding part of the gene ( $\sim 60 \mathrm{bp})$ encoding NsaC. Surprisingly, amplification of a $1.3 \mathrm{~kb}$ DNA fragment was achieved from the genomic DNA of strain BN6 with primer DHNDO1 alone, using a low annealing temperature $\left(35^{\circ} \mathrm{C}\right)$. The $1.3 \mathrm{~kb}$ PCR fragment was cloned into pUC18 and sequenced. Database searches demonstrated a significant homology of the encoded peptide to different bacterial 2,3-dihydroxybiphenyl-1,2-dioxygenases and NsaCs. Furthermore, these sequence comparisons demonstrated that the encoded protein was different from two other extradiol dioxygenases (BphC1 and BphC2) which were previously cloned from strain BN6 (Heiss et al., 1995, 1997).

\section{Isolation of the DNA region surrounding the gene encoding the NsaC}

A genomic library of the wild-type S. xenophaga BN6 was constructed using a $\lambda$ RES vector (Altenbuchner, 1993). The PCR fragment encoding the NsaC was labelled and used to screen the library. pAKE3-5 was identified, which carries the genomic context of the $n s a C$ gene. Using inverse PCR, $3.5 \mathrm{~kb}$ upstream and $1.5 \mathrm{~kb}$ downstream of the genomic insert of pAKE35.1 were identified and sequenced. This resulted in a total continuous DNA sequence of $16915 \mathrm{bp}$. The $\mathrm{G}+\mathrm{C}$ content of this DNA sequence was $57 \cdot 7 \%$, a value which is lower than the total $\mathrm{G}+\mathrm{C}$ content of the genomic DNA of $S$. xenophaga BN6 $(62 \cdot 1 \pm 0 \cdot 2 \%)$ (Stolz et al., 2000). Computer analysis revealed 15 complete (ORF2-ORF13, ORF15-ORF17), one partial (ORF1) and one disrupted (ORF14) ORFs. ORF10 and ORF11 were homologous to the $\mathrm{N}$ - and $\mathrm{C}$-terminal parts, respectively, of the large component of an oxygenase. This indicated that ORF10 and ORF11 are inactive fragments generated by an amber mutation ( $\mathrm{Q} \rightarrow$ stop) from the gene encoding the large component of a ring-hydroxylating aromatic oxygenase (Fig. 2). The deduced protein sizes of all identified proteins are summarized in Table 3. The identified genes are presumably organized in at least six different clusters. Two of the putative transcriptional units are separated by a putative rho-independent transcription terminator (http://www.bioinfo.rpi.edu/applications/mfold; Fig. 2).

\section{Construction of deletion mutants in the genes supposed to encode the initial NsaA}

S. xenophaga BN6 degrades (substituted) naphthalenesulfonates after an initial desulfonation via a modified naphthalene pathway with (substitituted) 1,2-dihydroxynaphthalene(s) as initial metabolite(s) (Nörtemann et al., 1986; Kuhm et al., 1991a). Thus, the initial desulfonating, ring-hydroxylating dioxygenase is of central importance in this pathway. Analysis of the $17 \mathrm{~kb}$ genomic sequence revealed several ORFs which shared significant homologies with different proteins of multicomponent dioxygenases. Thus, ORF6, ORF8, ORF9 and ORF16 demonstrated sequence similarities with the $\alpha$, ferredoxin, small and reductase components of ring-hydroxylating dioxygenases (Table 3). To analyse if these ORFs encode (parts of) the initial naphthalenesulfonate dioxygenase or different multicomponent dioxygenases, the corresponding genes were each deleted by site-specific integration mutagenesis and replaced by the kanamycin-resistance gene (nptII) of Tn5. The integration cassettes were constructed via gene splicing by overlap extension (Horton et al., 1989). The strains which were further analysed were designated AKE2 ( $\triangle$ ORF6), AKE3 ( $\triangle$ ORF9), AKE4 ( $\triangle$ ORF8) and AKE5 ( $\triangle$ ORF16). The integration of the nptII gene into each ORF was verified by Southern blot analysis, as described previously (Keck et al., 2002). 
(a)

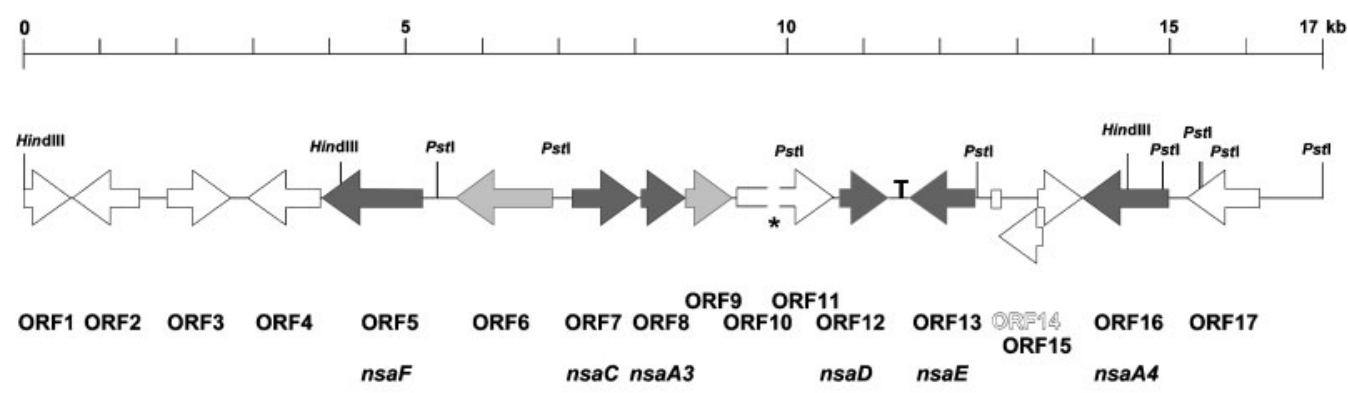

(b)

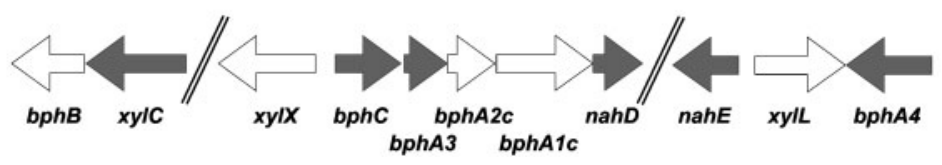

Fig. 2. (a) Genetic map of the 17 kb DNA fragment from S. xenophaga BN6. The positions and orientations of the identified ORFs are indicated by filled arrows. The putative $\alpha$ and $\beta$ subunits of a multicomponent dioxygenase are shaded in grey. ORF14, which is disrupted by ORF15, is indicated by a dotted outline. ORF10 and ORF11 are truncated genes of a dioxygenase and are shown as a single, non-functional ORF. The genes encoding proteins which have been shown to be involved in the degradation of naphthalenesulfonates (nsa genes) are displayed in italic type. Relevant restriction sites are shown. A rho-independent terminator-like structure $(T)$ is indicated between ORF12 and ORF13. (b) In comparison to the genes of the BN6 locus, homologous proteins which are encoded on three different, non-contiguous loci of pNL1 from $S$. aromaticivorans F199 are displayed. Homologous genes from strain F199 which encode proteins with functions similar to those of the nsa genes are shaded.

\section{Biochemical analysis of the deletion mutants in the genes presumably encoding NsaA}

The conversion of 2NSA by cell suspensions of the integration mutants AKE2 ( $\triangle$ ORF6::nptII), AKE3 ( $\triangle$ ORF9::nptII), AKE4 $(\Delta \mathrm{ORF} 8:: n p t I I)$ and AKE5 $(\Delta \mathrm{ORF} 16:: n p t I I)$ was tested. Resting cells of these strains were analysed for NsaA activity and the corresponding cell extracts were analysed for NsaC, NsaE and NsaF activity. The addition of salicylate induced $\mathrm{NsaC}, \mathrm{NsaE}$ and $\mathrm{NsaF}$ activities in the mutant and wild-type strains (Table 4). NsaA activity was only detected with resting cells of strains AKE2, AKE3 and the wild-type strain. Strains AKE4 and AKE5 did not show any measurable NsaA activity, irrespective of the presence of salicylate. These results strongly support the view that ORF8 and ORF16 encode the ferredoxin (nsaA3) and reductase (nsaA4) components of NsaA, whereas ORF6 and ORF9 might encode the oxygenase component of a not-yet-identified ringhydroxylating dioxygenase.

\section{In silico identification of the genes encoding the NsaC, NsaD, NsaE and NsaF involved in the degradation of naphthalenesulfonates}

$\mathrm{NsaC}$ and NsaE from S. xenophaga BN6 have previously been purified and their $\mathrm{N}$-terminal amino acid sequences determined (Kuhm et al., 1991a, 1992). This allowed the identification of ORF7 and ORF13 as the genes encoding the $\mathrm{NsaC}$ and $\mathrm{NsaE}$ of the naphthalenesulfonate pathway, because the $\mathrm{N}$-terminal 29 or 26 aa of the predicted protein sequences were identical to the data obtained experimentally by protein sequencing. Furthermore, the predicted molecular masses of the proteins encoded by ORF7 (33 $301 \mathrm{Da}$ ) and ORF13 (35459 Da) were in good agreement with the values of 33000 and 38500 Da determined experimentally for the purified NsaC and NsaE (Kuhm et al., 1991a, 1992).

The amino acid sequence of ORF12 shared significant homologies to different NsaDs (Table 3), such as NahD from S. aromaticivorans F199 and Sphingomonas sp. CHY-1 (76-77\% identical residues). ORF5 shared the highest degree of homology with different presumed benzaldehyde or salicylaldehyde dehydrogenases from different sphingomonads (Table 3). Thus, it appeared that all enzymes necessary for the conversion of (substituted) 1,2-dihydroxynaphthalene(s) to (substituted) salicylate(s) were encoded on the analysed DNA fragment.

\section{Experimental identification of the genes encoding the NsaC, NsaD, NsaE and NsaF involved in the degradation of naphthalenesulfonates}

The genes encoding the putative $\mathrm{NsaC}, \mathrm{NsaD}, \mathrm{NsaE}$ and NsaF were amplified from genomic DNA of strain BN6 via PCR (Table 2). The genes were integrated into the expression plasmid pJOE2702 (Volff et al., 1996) to give pAKE16 (ORF5), pJKS325 (ORF7), pAKE18 (ORF12) and pAKE17 
Table 3. Identified genes and gene products of the sequenced $17 \mathrm{~kb}$ DNA fragment

\begin{tabular}{|c|c|c|c|c|c|c|}
\hline ORF & $\begin{array}{l}\text { Position (bp) } \\
\text { (accession no. } \\
\text { U65001) }\end{array}$ & $\begin{array}{l}\text { Calculated } \\
\text { molecular } \\
\text { mass }(\mathrm{Da})\end{array}$ & Putative function & Homologous proteins & $\begin{array}{l}\text { Amino acid } \\
\text { identity } \\
(\%)\end{array}$ & $\begin{array}{c}\text { GenBank } \\
\text { accession no. }\end{array}$ \\
\hline \multirow[t]{2}{*}{ ORF1 (incomplete) } & $1-423$ & $>15683$ & Transposon-associated ATP-binding protein & Y4sD of Rhizobium sp. NGR234 & 78 & NP_444057.1 \\
\hline & & & & $\begin{array}{l}\text { Putative transposase from Bradyrhizobium } \\
\text { japonicum USDA } 110\end{array}$ & 79 & NP_771639.1 \\
\hline \multirow[t]{2}{*}{ ORF2 } & $498-1424 \mathrm{C}^{\star}$ & 35229 & Transposon-associated ATP-binding protein & $\begin{array}{l}\text { Putative insertion sequence ATP-binding protein } \\
\text { from Rhizobium etli }\end{array}$ & 77 & AAM54812.1 \\
\hline & & & & $\begin{array}{l}\text { Putative site-specific recombinase from } \\
\text { Sinorhizobium meliloti } 1021\end{array}$ & 44 & NP_435669.1 \\
\hline \multirow[t]{2}{*}{ ORF3 } & $1929-2606$ & 25518 & Transposase & Putative transposase of Burkholderia cepacia R1808 & 66 & ZP_00219685.1 \\
\hline & & & & Transposase of Janthinobacterium sp. J3 & 63 & BAC56751.1 \\
\hline \multirow[t]{2}{*}{ ORF4 } & $3035-3836 \mathrm{C}$ & 27972 & 1,2-Dihydrodiol-1,2-dihydroxydehydrogenase & BphB of S. aromaticivorans F199 & 75 & AF079317 \\
\hline & & & & $\begin{array}{l}\text { Short-chain alcohol dehydrogenase of } S \text {. aromatici- } \\
\text { vorans DSM } 12444\end{array}$ & 69 & ZP_00302761.1 \\
\hline \multirow[t]{2}{*}{ ORF5 } & $3875-5374 \mathrm{C}$ & 54223 & NsaF & $\begin{array}{l}\text { Benzaldehyde dehydrogenase of S. aromaticivorans } \\
\text { DSM } 12444\end{array}$ & 84 & ZP_00302762.1 \\
\hline & & & & $\begin{array}{l}\text { Benzaldehyde dehydrogenase of Sphingomonas } \\
\text { chungbukensis }\end{array}$ & 81 & AAD03838.2 \\
\hline \multirow[t]{2}{*}{ ORF6 } & 5755-7167 C & 52713 & Multicomponent dioxygenase $\alpha$ component & XylX of Sphingomonas sp. P2 & 80 & BAC65430 \\
\hline & & & & XylX of S. aromaticivorans F199 & 68 & AF079317 \\
\hline \multirow[t]{2}{*}{ ORF7 } & $7467-8363$ & 33301 & $\mathrm{NsaC}$ & BphC of Sphingomonas sp. P2 & 85 & BAC65429.1 \\
\hline & & & & BphC of 'Sphinogomonas paucimobilis' Q1 & 85 & M20640 \\
\hline \multirow[t]{2}{*}{ ORF8 } & $8420-8746$ & 11595 & Ferredoxin component of a dioxygenase & BphA3 of Sphingomonas sp. P2 & 82 & BAC65428.1 \\
\hline & & & & BphA3 of S. chungbukensis $\mathrm{CHY}-1$ & 78 & CAG17580.1 \\
\hline \multirow[t]{2}{*}{ ORF9 } & $8748-9236$ & 18724 & $\beta$ component of a dioxygenase & BphA2 of Sphingomonas sp. P2 & 82 & BAC65427.1 \\
\hline & & & & $\begin{array}{l}\text { Small component of a phenylpropionate } \\
\text { dioxygenase of S. aromaticivorans DSM } 12444\end{array}$ & 66 & ZP_00302780.1 \\
\hline \multirow[t]{2}{*}{$\begin{array}{l}\text { ORF10 ( } 5^{\prime} \text { end of } \\
\text { a truncated gene) }\end{array}$} & $9258-9656$ & 14864 & Large component of a dioxygenase & $\begin{array}{l}\text { Large component of an oxygenase from } \\
\text { Sphingomonas sp. P2 }\end{array}$ & 78 & BAC65426.1 \\
\hline & & & & $\begin{array}{l}\text { Large component of an oxygenase from } S \text {. } \\
\text { aromaticivorans F199 (aa 1-132) }\end{array}$ & 77 & AAD04009.1 \\
\hline \multirow[t]{2}{*}{$\begin{array}{l}\text { ORF11 ( } 3^{\prime} \text { end of } \\
\text { a truncated gene) }\end{array}$} & $9663-10520$ & 31739 & Large component of a dioxygenase & $\begin{array}{l}\text { Large component of an oxygenase from } \\
\text { Sphingomonas sp. P2 }\end{array}$ & 88 & BAC65426.1 \\
\hline & & & & $\begin{array}{l}\text { Large component of a phenylpropionate } \\
\text { dioxygenase from S. aromaticivorans DSM } \\
12444 \text { (aa 135-420) }\end{array}$ & 84 & ZP_00302781.1 \\
\hline \multirow[t]{2}{*}{ ORF12 } & $10517-11104$ & 22064 & NsaD & NahD of S. aromaticivorans DSM 12444 & 77 & ZP_00302782.1 \\
\hline & & & & NahD of Sphingomonas sp. CHY-1 & 76 & CAG17583.1 \\
\hline ORF13 & $11462-12448 \mathrm{C}$ & 35459 & 2'-Hydroxybenzalpyruvate aldolase & NahE of Sphingomonas sp. P2 & 89 & BAC65452.1 \\
\hline
\end{tabular}


(ORF13) (Table 5). The corresponding strains E. coli JM109(pAKE16), JM109(pJKS325), JM109(pAKE18) and JM109(pAKE17) were each grown to the early exponential growth phase and induced by the addition of rhamnose (see Methods). The cell extracts were analysed via SDS-PAGE. Additional proteins of the predicted sizes were only present in cell extracts of the rhamnose-induced strains (Fig. 3). The corresponding enzyme activity was analysed in comparison to cell extracts of the uninduced strain E. coli JM109(pJOE2702). As summarized in Table 5, the putative enzyme functions were confirmed for ORF7 (NsaC), ORF12 (NsaD), ORF13 (NsaE) and ORF5 (NsaF). The cell extracts of the uninduced strains and the control strain JM109(pJOE2702) did not show any NsaC, NsaD, NsaE or NsaF activity.

\section{DISCUSSION}

The results of the present study of the genes encoding the degradative pathway for naphthalenesulfonates by $S$. xenophaga $\mathrm{BN} 6$, in combination with those of previous studies of the molecular organization of the genes responsible for the degradation of naphthalene and biphenyl by $S$. aromaticivorans F199 (Romine et al., 1999) and phenanthrene by Sphingomonas sp. P2 (Pinyakong et al., 2003a), clearly demonstrate a unique conserved organization of the genes involved in the degradation of bicyclic and polycyclic aromatic compounds by sphingomonads. Thus, in all three strains, three conserved gene clusters were identified, which shared significant nucleotide sequence identities ranging from 60 to $90 \%$. One of these gene clusters has also recently been identified in the chrysene-degrading strain Sphingomonas sp. CHY-1 (Demanèche et al., 2004), and a similar genetic organization also seems to be present in the biphenyl-degrading strain Sphingomonas yanoikuyae B1 (Kim \& Zylstra, 1999), although unfortunately the relevant gene sequence has not yet been deposited in a public database. Furthermore, some recent PCR experiments, using primers derived from conserved sequences within these gene clusters, suggest that these gene clusters are also present in other aromatic-degrading sphingomonads (although in different arrangements and at different distances from each other) (Basta et al., 2005). The conservation of these gene clusters among different sphingomonads is also reflected by the results of the amino acid sequence comparisons of the proteins of the S. xenophaga BN6 aromatic degradation pathway and the sequences deposited at the NCBI database. These alignments always resulted in the identification of genes from other sphingomonads as the most closely related sequences. This clearly demonstrates that, although the relevant genes are encoded on plasmids in S. aromaticivorans F199 and S. xenophaga BN6 (Romine et al., 1999; Basta et al., 2004), some restrictions seem to occur which prevent a broad dissemination of the relevant genetic information among bacterial strains which do not belong to the sphingomonads. This was also indicated by our failure to transfer Sphingomonas plasmids labelled with antibiotic resistance markers to bacterial strains not belonging to the 
Table 4. Biochemical characterization of different mutations in the genes putatively encoding NsaA

The strains were cultivated, and induced by addition of salicylate $(0.5 \mathrm{mM})$, as described in Methods. sal, salicylate.

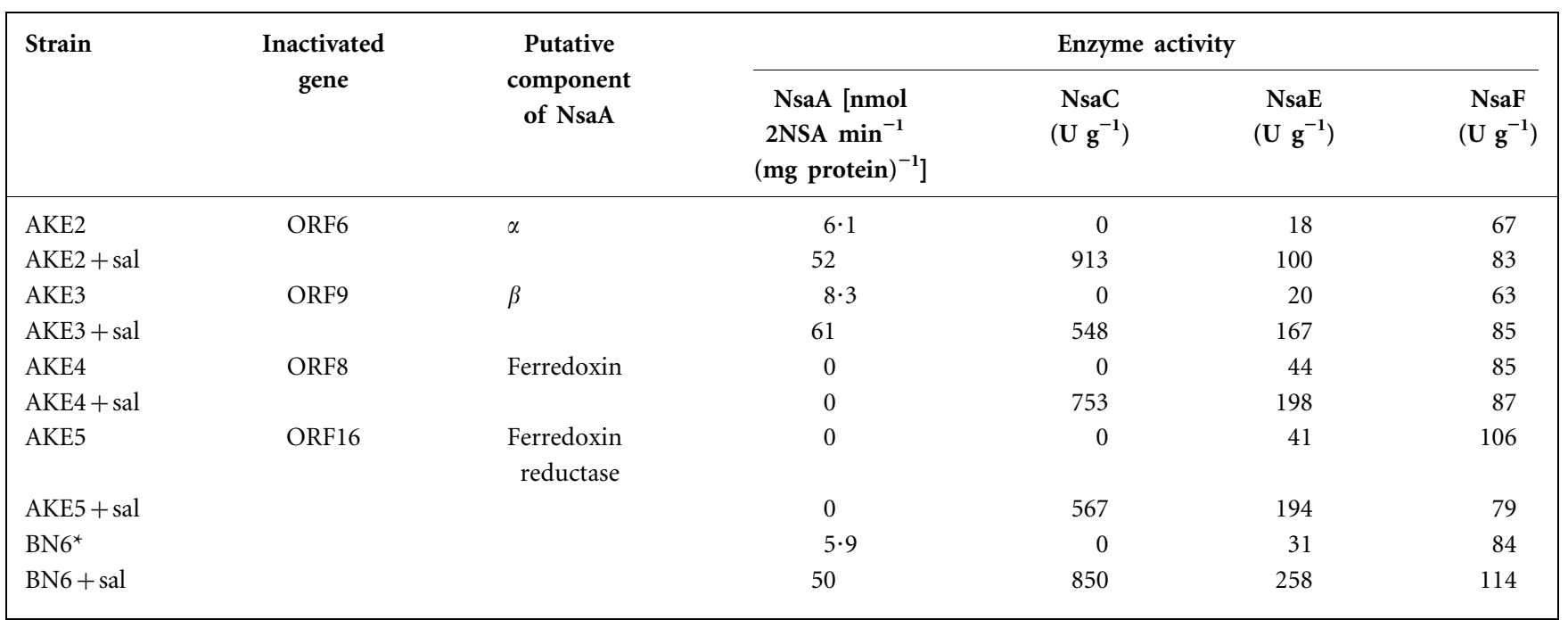

${ }^{\star}$ The wild-type of S. xenophaga BN6 was used as positive control.

Sphingomonadaceae (Basta et al., 2004). Thus, the organization of the genes and the sequence comparisons of the individual genes both suggest some unique lines of evolution for the degradation of aromatics among the sphingomonads.

The previous work with S. aromaticivorans F199 and Sphingomonas sp. P2 was mainly concerned with the sequencing of the relevant parts of the bacterial genomes, and the putative functions of the identified genes were almost exclusively deduced from their homologies with genes of known function from the databases. In contrast to this situation, for S. xenophaga BN6, much more biochemical data were available from previous studies. This, together with the extensive generation of mutants performed in the course of the present study, allowed an unequivocal identification of the $n s a C$ and $n s a E$ genes participating in the degradation of the naphthalenesulfonates.

Table 5. Rhamnose-inducible expression of the genes ORF5, ORF7, ORF12 and ORF13 using pJOE2702 (Volff et al., 1996)

The enzyme activities of the corresponding cell extracts are summarized. ND, Not determined.

\begin{tabular}{|lccccc|}
\hline \multirow{2}{*}{ ORF } & \multirow{2}{*}{ Plasmid } & \multicolumn{4}{c|}{ Enzyme activity $\left(\mathbf{U ~ m g}^{-\mathbf{1}}\right)$} \\
\cline { 3 - 6 } & & NsaF & NsaC & NsaD & NsaE \\
\hline ORF5 & pAKE16 & 2 & ND & ND & ND \\
ORF7 & pJKS327 & ND & 39 & ND & ND \\
ORF12 & pAKE18 & ND & ND & $5 \cdot 4$ & ND \\
ORF13 & pAKE17 & ND & ND & ND & 1 \\
\hline
\end{tabular}

This furnished the final experimental proof that these two genes are indeed not part of the same operon in various sphingomonads.

The phenotypic analysis of the mutants clearly suggested that ORF8 and ORF16 encode the ferredoxin (nsaA3) and ferredoxin reductase ( $n s a A 4)$, respectively, of the initial desulfonating NsaA, because these mutants no longer

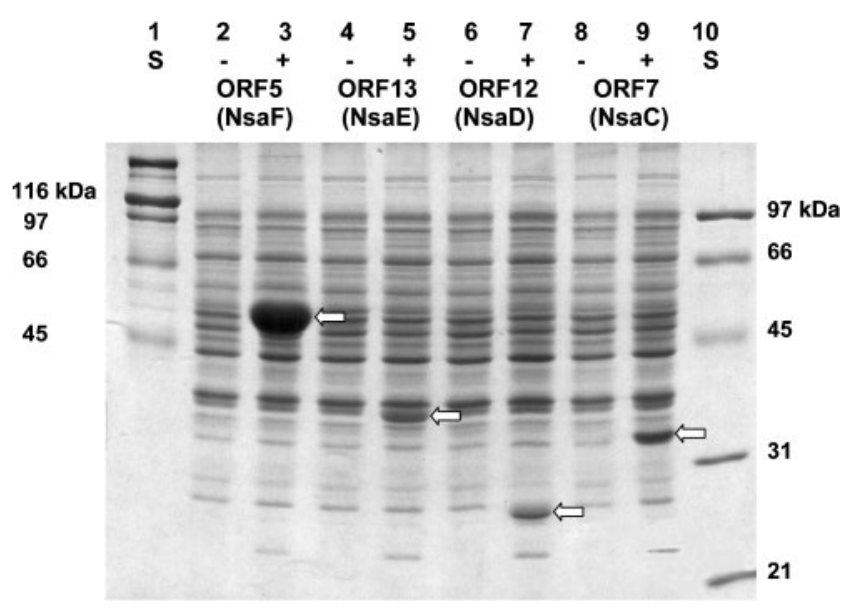

Fig. 3. SDS-PAGE (12\%) of crude extracts of strains JM109(pAKE16) (lanes 2 and 3), JM109(pAKE17) (lanes 4 and 5), JM109(pAKE18) (lanes 6 and 7) and JM109(pJKS325) (lanes 8 and 9) from rhamnose-induced (+) or uninduced (-) cells. Molecular mass standard (S) was obtained from Bio-Rad. The sizes and positions of the marker proteins are indicated to the left and right. The positions of the ORF5-, ORF7-, ORF12and ORF13-encoded proteins are indicated by arrows. 
converted 2NSA. This demonstrated that the genes encoding the ferredoxin and ferredoxin reductase also belong to different gene clusters. In contrast, the mutations in ORF6 and ORF9 (which presumably encode the large and small components, respectively, of a hydroxylating oxygenase) clearly demonstrated that these ORFs either do not encode the initial desulfonating activity or can be replaced by some other (redundant) activity. A similar observation was made when the putative oxygenase gene of a ring-hydroxylating dioxygenase from $S$. yanoikuyae B1 was deleted, but no influence on the ability of the strain to oxidize naphthalene or biphenyl was found. The analysis of the relevant gene sequence from S. yanoikuyae B1 demonstrated the presence of at least six oxygenase components of ring-hydroxylating dioxygenases (XylXY, BphA1a2a, BphA1b2b, BphA1c, BphAld and BphA1e). On the other hand, there is only one copy of the genes specifying the ferredoxin $(b p h A 3)$ and ferredoxin reductase (bphA4) (Zylstra \& Kim, 1997). Thus, analysis of the relevant genomic regions of $S$. aromaticivorans F199 (and also of Sphingomonas sp. P2) suggests that various terminal oxygenases can be synthesized by these strains (Romine et al., 1999; Pinyakong et al., 2003a). These findings indicate that it is a general concept in the metabolism of aromatic compounds by sphingomonads to couple a unique electron transport system (consisting of a ferredoxin and a ferredoxin reductase) with multiple oxygenase components (presumably with different substrate specificities). Thus, it is probable that the genes for the large and small components of the NsaA are located in $S$. xenophaga BN6 at a different position.

The analysed DNA fragment from S. xenophaga BN6 encoded, in addition to ORF6 and ORF9, which were analysed by deletion mutagenesis, two more ORFs (ORF10 and ORF11) which demonstrated homology to large components of ring-hydroxylating oxygenases. The sequence comparisons suggested that the proteins encoded by ORF10 and ORF11 are significantly truncated in comparison to classical, functional, large components of ring-hydroxylating oxygenases. Thus, ORF10 may encode only a protein of 132 aa and ORF11 a protein of 285 aa. The sequence alignments suggested that ORF10 and ORF11 are homologous to the $\mathrm{N}$ - and C-terminal parts, respectively, of the large component of an oxygenase. This indicated that ORF10 and ORF11 are inactive fragments generated by an amber mutation $(\mathrm{Q} \rightarrow$ stop $)$ from the gene encoding the large component of a ring-hydroxylating aromatic oxygenase. The BLAST searches indicated that both ORF10 and ORF11 show the highest degree of sequence identity with AhdA1c from Sphingomonas sp. P2. Furthermore, we found that ORF9 from strain BN6 showed the highest degree of homology to the small component (AhdA2c) of the same oxygenase from Sphingomonas sp. P2. This indicated that $S$. xenophaga BN6 only possesses an inactivated derivative of the enzyme from Sphingomonas sp. P2. Interestingly, it has recently been shown that AhdA1c and AhdA2c encode a monooxygenase in Sphingomonas sp. P2 which converts (substituted) salicylate(s) to (substituted) catechol(s)
(Pinyakong et al., 2003b). Thus, the amber mutation between ORF10 and ORF11 might be responsible for the inability of $S$. xenophaga BN6 to oxidize (substituted) salicylate(s) which are formed from (substituted) naphthalenesulfonate(s) (Nörtemann et al., 1986, 1994). This is of central importance for the ability of this strain to establish stable mixed bacterial cultures with salicylate-degrading bacteria and, presumably, is also responsible for the ability of strain BN6 to convert a wide range of substituted naphthalenesulfonates.

It was previously demonstrated that the genes responsible for the degradation of naphthalenesulfonates are encoded on a $180 \mathrm{~kb}$ plasmid (pBN6) in S. xenophaga BN6 (Basta et al., 2004). The sequence analysis performed during the present work suggested that the genes encoding the degradation of naphthalenesulfonates are flanked by genes (ORF1, ORF2, ORF3 and ORF17) specifying proteins with homologies to proteins encoded by transposons or insertion elements (Table 4). The presence of such genes suggests that the identified $n s a$ genes may be part of functional or non-functional mobile genetic elements. Similar genetic arrangements might also be responsible for the previous observations that the genes encoding the degradative pathway(s) for naphthalene (and biphenyl) are either found on the chromosome or on large plasmids of certain sphingomonads (Kim et al., 1996). The pronounced rearrangements which have been observed after the transfer of plasmids among sphingomonads might be due to these special structural features and homologies (Feng \& Ogram, 1997; Basta et al., 2004).

\section{REFERENCES}

Alonso, M. C., Castillo, M. \& Barceló, D. (1999). Solid-phase extraction procedure of polar benzene- and naphthalenesulfonates in industrial effluents followed by unequivocal determination with ion-pair chromatography/electrospray-mass spectrometry. Anal Chem 71, 2586-2593.

Altenbuchner, J. (1993). A new $\lambda$ RES vector with a built-in Tn1721encoded excision system. Gene 123, 63-68.

Altenbuchner, J., Vieill, P. \& Pelletier, I. (1992). Positive selection vectors based on palindromic DNA sequences. Methods Enzymol 216, 457-466.

Altschul, S. F., Gish, W., Miller, W., Myers, E. W. \& Lipmann, D. J. (1990). Basic local alignment search tool. J Mol Biol 215, 403-410.

Basta, T., Keck, A., Klein, J. \& Stolz, A. (2004). Detection and characterization of conjugative degradative plasmids in xenobioticsdegrading Sphingomonas strains. J Bacteriol 186, 3862-3872.

Basta, T., Bürger, S. \& Stolz, A. (2005). Structural and replicative diversity of large plasmids from sphingomonads that degrade polycyclic aromatic compounds and xenobiotics. Microbiology 151, 2025-2037.

Bradford, M. M. (1976). A rapid and sensitive method for the quantification of microgram quantities of protein utilizing the principle of protein-dye binding. Anal Biochem 72, 248-254.

Brilon, C., Beckmann, W. \& Knackmuss, H. J. (1981a). Catabolism of naphthalenesulfonic acids by Pseudomonas sp. A3 and Pseudomonas sp. C22. Appl Environ Microbiol 42, 44-55. 
Brilon, C., Beckmann, W., Hellwig, M. \& Knackmuss, H. J. (1981b). Enrichment and isolation of naphthalenesulfonic acid-utilizing pseudomonads. Appl Environ Microbiol 42, 39-43.

Chung, C. T., Niemela, S. L. \& Miller, R. H. (1989). One-step preparation of competent Escherichia coli: transformation and storage of bacterial cells in the same solution. Proc Natl Acad Sci U S A 86, 2172-2175.

Demanèche, S., Meyer, C., Micoud, J., Louwagie, M., Willison, J. C. \& Jouanneau, Y. (2004). Identification and functional analysis of two aromatic-ring-hydroxylating dioxygenases from a Sphingomonas strain that degrades various polycyclic aromatic hydrocarbons. Appl Environ Microbiol 70, 6714-6725.

Dorn, E., Hellwig, M., Reinecke, W. \& Knackmuss, H.-J. (1974). Isolation and characterization of a 3-chlorobenzoate degrading pseudomonad. Arch Microbiol 99, 61-70.

Feng, X. \& Ogram, A. (1997). Plasmid mediated mineralization of carbofuran by Sphingomonas sp. strain CF06. Appl Environ Microbiol 63, 1332-1337.

Gish, W. \& States, D. J. (1993). Identification of protein coding regions by database similarity search. Nat Genet 3, 266-272.

Heiss, G., Stolz, A., Kuhm, A. E., Müller, C., Klein, J., Altenbuchner, J. \& Knackmuss, H.-J. (1995). Characterization of a 2,3-dihydroxybiphenyl dioxygenase from the naphthalenesulfonate-degrading bacterium strain BN6. J Bacteriol 177, 5865-5871.

Heiss, G., Müller, C., Altenbuchner, J. \& Stolz, A. (1997). Analysis of a new dimeric extradiol dioxygenase from a naphthalenesulfonatedegrading sphingomonad. Microbiology 143, 1691-1699.

Hils, M. (1998). Mutanten der D-Carbamoylase zur Bildung aktiven Enzyms bei Expression des Gens in Escherichia coli und Analyse eines Genclusters für die Enzyme des Hydantoin-Abbaus aus Agrobacterium sp. I-671. PhD thesis, University of Stuttgart.

Horton, R. M., Hunt, H. D., Ho, S. N., Pullen, J. K. \& Pease, L. R. (1989). Engineering hybrid genes without the use of restriction enzymes: gene splicing by overlap extension. Gene 77, 61-68.

Keck, A., Klein, J., Kudlich, M., Stolz, A., Knackmuss, H.-J. \& Mattes, R. (1997). Reduction of azo dyes by redox mediators originating in the naphthalenesulfonic acid degradation pathway of Sphingomonas sp. BN6. Appl Environ Microbiol 63, 3684-3690.

Keck, A., Rau, J., Reemtsma, T., Mattes, R., Stolz, A. \& Klein, J. (2002). Identification of quinoide redox mediators that are formed during the degradation of naphthalene-2-sulfonate by Sphingomonas xenophaga BN6. Appl Environ Microbiol 68, 4341-4349.

Kieser, T. (1984). Factors affecting the isolation of CCC DNA from Streptomyces lividans and Escherichia coli. Plasmid 12, 19-36.

Kim, E. \& Zylstra, G. J. (1999). Functional analysis of genes involved in biphenyl, naphthalene, phenanthrene, and $\mathrm{m}$-xylene degradation by Sphingomonas yanoikuyae B1. J Ind Microbiol Biotechnol 23, 294-302.

Kim, E., Aversano, P. J., Romine, M. F., Schneider, R. P. \& Zylstra, G. J. (1996). Homology between genes for aromatic hydrocarbon degradation in surface and deep-subsurface Sphingomonas strains. Appl Environ Microbiol 62, 1467-1470.

Kuhm, A. E., Stolz, A. \& Knackmuss, H.-J. (1991a). Metabolism of naphthalene by the biphenyl-degrading bacterium Pseudomonas paucimobilis Q1. Biodegradation 2, 115-120.

Kuhm, A. E., Stolz, A., Ngai, K.-L. \& Knackmuss, H.-J. (1991b). Purification and characterization of a 1,2-dihydroxynaphthalene dioxygenase from a bacterium that degrades naphthalenesulfonic acids. J Bacteriol 173, 3795-3802.

Kuhm, A. E., Knackmuss, H.-J. \& Stolz, A. (1992). Purification and properties of 2 '-hydroxybenzalpyruvate aldolase from a bacterium that degrades naphthalenesulfonates. J Biol Chem 268, 9484-9489.
Kuhm, A. E., Knackmuss, H.-J. \& Stolz, A. (1993). 2-Hydroxychromene-2-carboxylate isomerase from bacteria that degrade naphthalenesulfonates. Biodegradation 4, 155-162.

Laemmli, U. K. (1970). Cleavage of structural proteins during the assembly of the head of bacteriophage T4. Nature 227, 680-685.

Nicholas, K. B. \& Nicholas, H. B., Jr (1996). GENEDOC: a tool for editing and annotating multiple sequence alignments. Distributed by the author per anonymous ftp (http://www.psc.edu/biomed/genedoc). Nörtemann, B., Baumgarten, J., Rast, H. G. \& Knackmuss, H.-J. (1986). Bacterial communities degrading amino- and hydroxynaphthalene-2-sulfonates. Appl Environ Microbiol 52, 1195-1201.

Nörtemann, B., Kuhm, A. E., Knackmuss, H.-J. \& Stolz, A. (1994). Conversion of substituted naphthalenesulfonates by Pseudomonas sp. BN6. Arch Microbiol 161, 320-327.

Ochman, H., Gerber, A. S. \& Hartl, D. L. (1988). Genetic applications of inverse polymerase chain reaction. Genetics 120, 621-623.

Ohe, T. \& Watanabe, Y. (1986). Degradation of 2-naphthylamine-1sulfonic acid by Pseudomonas strain TA-1. Agric Biol Chem 50, 1419-1425.

Ohe, T. \& Watanabe, Y. (1988). Microbial degradation of 1,6- and 2,6-naphthalenedisulfonic acid by Pseudomonas sp. DS-1. Agric Biol Chem 52, 2409-2414.

Pinyakong, O., Habe, H. \& Omori, T. (2003a). The unique aromatic catabolic genes in sphingomonads degrading polycyclic aromatic hydrocarbons (PAHs). J Gen Appl Microbiol 49, 1-19.

Pinyakong, O., Habe, H., Yoshida, T., Nojiri, H. \& Omori, T. (2003b). Identification of three isofunctional novel salicylate 1-hydroxylases involved in the phenanthrene degradation of Sphingobium sp. strain P2. Biochem Biophys Res Commun 201, 350-357.

Riediker, S., Suter, M. J.-F. \& Giger, W. (2000). Benzene- and naphthalenesulfonates in leachates and plumes of landfills. Wat Res 34, 2069-2079.

Romine, M. F., Stillwell, L. C., Wong, K. K., Thurston, S. J., Sisk, E. C., Sensen, C., Gaasterland, T., Fredrickson, J. K. \& Saffer, J. D. (1999). Complete sequence of a 184-kilobase catabolic plasmid from Sphingomonas aromaticivorans F199. J Bacteriol 181, 1585-1602.

Ruckstuhl, S. M., Suter, J.-F., Kohler, H.-P. E. \& Giger, W. (2002). Leaching and primary biodegradation of sulfonated naphthalenes and their formaldehyde condensates from concrete superplasticizers in groundwater affected by tunnel construction. Environ Sci Technol 36, 3284-3289.

Sambrook, J., Fritsch, E. F. \& Maniatis, T. (1989). Molecular Cloning: a Laboratory Manual, 2nd edn. Cold Spring Harbor, NY: Cold Spring Harbor Laboratory.

Simon, R., Priefer, U. \& Pühler, A. (1983). A broad-host-range mobilization system for in vivo genetic engineering and transposon mutagenesis in gram-negative bacteria. Bio/Technology 1, 784-791.

Stolz, A. (1999). Degradation of substituted naphthalenesulfonic acids by Sphingomonas xenophaga BN6. J Ind Microbiol Biotechnol 23, 391-399.

Stolz, A., Schmidt-Maag, C., Denner, E. B. M., Busse, H.-J., Egli, T. \& Kämpfer, P. (2000). Description of Sphingomonas xenophaga sp.nov for strains $\mathrm{BN}^{\mathrm{T}}$ and $\mathrm{N}, \mathrm{N}$ which degrade xenobiotic aromatic compounds. Int J Syst Bacteriol 50, 35-41.

Thomson, J. D., Higgins, D. G. \& Gibson, T. J. (1994). ClustalW: improving the sensitivity of progressive multiple sequence alignment through sequence weighting, position specific gap penalties and weight matrix choice. Nucleic Acids Res 22, 4673-4680.

Tully, P. S. (1997). Sulfonic acids. In Kirk-Othmer Encylopedia of Chemical Technology, 4th edn, vol. 23, pp. 194-217. New York: Wiley. 
Vieira, J. \& Messing, J. (1982). The pUC plasmids and M13mp7derived system for insertion mutagenesis and sequencing with synthetic universal primers. Gene 19, 259-268.

Volff, J.-N., Eichenseer, C., Viell, P., Piendl, W. \& Altenbuchner, J. (1996). Nucleotide sequence and role in DNA amplification of the direct repeats composing the amplifiable element AUD1 of Streptomyces lividans 66. Mol Microbiol 21, 1037-1047.

Wada, K., Wada, Y., Ishibashi, F., Gojobori, T. \& Ikemura, T. (1992). Codon usage tabulated from the Genbank genetic sequence data. Nucleic Acids Res 20, 2111-2118.

Wellens, H. (1990). Zur biologischen Abbaubarkeit mono- und disubstituierter Benzolderivate. Z Wasser-Abwasser Forsch 23, 85-98.
Wittich, R. M., Rast, H. G. \& Knackmuss, H.-J. (1988). Degradation of naphthalene-2,6- and naphthalene-1,6-disulfonic acid by a Moraxella sp. Appl Environ Microbiol 54, 1842-1847.

Yanisch-Perron, C., Vieira, J. \& Messing, J. (1985). Improved M13 phage cloning vectors and host strains: nucleotide sequences of the M13mp18 and pUC vectors. Gene 33, 103-119.

Zürrer, D., Cook, A. M. \& Leisinger, T. (1987). Microbial desulfonation of substituted naphthalenesulfonic acids and benzenesulfonic acids. Appl Environ Microbiol 53, 1459-1463.

Zylstra, G. J. \& Kim, E. (1997). Aromatic hydrocarbon degradation by Sphingomonas yanoikuyae B1. J Ind Microbiol Biotechnol 19, 408-414. 